\title{
Study on the Task-Based Teaching of College English on the Basis of Constructivism Theory
}

\author{
H.M. Zhao \\ Teaching and Research Institute of Foreign Languages \\ Bohai University \\ Jinzhou, China
}

\begin{abstract}
Currently, the society puts forward more demands for the personnel. But the current model of college English teaching is too outdated and the students' enthusiasm of language learning is very low and the teaching mode can not improve the comprehensive ability of students. In this paper, the author discusses the task-based teaching mode on the basis of constructivism theory and suggests some strategies on the different stages of task-based language teaching, and hopes it can be helpful to the college English teaching.
\end{abstract}

Keywords-task-based teaching; constructivism theory; collaboration study; situation

\section{INTRODUCTION}

With the rapid development of the market economy and deepening of the reform \&opening-up, the society demand for English personnel is increasing and the requirements are also increasingly stringent. English personnel not only need advanced English professional knowledge, but also have high skill ability in listening, speaking, reading, writing and translation. So it is the key of college English education to cultivate the English personnel with comprehensive ability. Although English education has been focused after the reform \&opening-up in China, the teaching mode has long stayed in the traditional teaching mode. And the mode of examinationoriented education has led to the facts that the college English teachers only pay attention to the pass of CET4 \&CET6 but ignore the cultivation of English ability. Teachers in colleges only teach the examination skills to students but do not care about the English ability of students. Consequently, the English ability of students is very poor and they can not successfully communicate with foreigners in English. At the same time, the traditional English teaching does not stimulate the learning initiative and enthusiasm of students, and therefore many students are weary of English and not interested in English learning. It becomes the key of English teaching reform how to improve the English comprehensive ability of college students and enhance their English application ability. The college English task-based teaching mode can well solve the insufficiency of English ability and improve the learning enthusiasm and initiative of students.

\section{THE THEORY OF CONSTRUCTIVISM AND ITS TEACHING CONCEPTS}

Constructivism is a cognitive psychology based on psychology, philosophy and anthropology. It has the profound influence on the research of human cognitive behavior. In the early of 1960s, Piaget, the Swiss psychologist, put forward the theory of cognitive development when he studied the cognitive behavior of children. His theory absorbed the theory of Vygotsky's historical and cultural psychology theory and the meaningful learning theory of Ausubel as well as Bruner's discovery learning theory. Therefore, the constructivism theory can well explain the cognitive rule of human learning. Ausubel held that the learner acquired knowledge is the most important factor that influences learning. He advocated that learning should be carried out on the basis of understanding. He opposed the meaningless imitation in learning. According to his opinion, teacher should teach students in accordance of their learners' available knowledge. Then Bruner put forward the 'basic structure' and 'learner centered' theory. He held that the enthusiasm and initiative of students should be fully exerted in learning behaviors. So the learners should observe, analyze, induct and discover the law by themselves. Therefore, he advocated the 'discovery learning'.

Piaget held that the development of cognition structure of children is the result of interaction between subject and object. The development process of children's psychological thinking and intelligence is the constant process of assimilation and adaptation for the objective world. Therefore, the process of knowledge construction is the adaptation process between the people and the nature, and also is the process of self reorganization for knowledge construction. Vygotsky held that the cognition development of children is the interaction result between individual and social culture. He held that the learning should be cooperative learning, rather than individual learning. So the most effective way is the combination learning of children and adult. Constructivism holds that thinking ability depends on the physical development and social experience of people. So the formation of personal knowledge does not depend on the unity of objective world, but depends on the understanding formed through the exchanges and collaboration between individual and others.

Constructivism holds that knowledge is not taught by teachers, but achieved through the meaning construction, which is conducted under certain social culture background, helped by others and use the necessary learning materials. If the leaner takes the initiative to construct the knowledge structure, the new knowledge structure is not only robust against degradation but also provides the learner the opportunity to learn actively. This can develop the creative thinking ability for the students. Because learning is the meaning construction process that happens with the help of others in certain situation, the constructivism theory believes that situation, collaboration, conversation and meaning construction are the four parts of 
learning environment. Learning should be carried out in certain situation. The real situation would be best. Learning should be conducted through collaboration and conversation with the people around, and students are the main body of meaning construction. The teacher becomes the facilitator and helper rather than the sender of knowledge in learning of students. Constructivism advocates that learning the new knowledge should be based on the personal experiences and existing knowledge structure of learner. It emphasizes the cultivation of learner's ability in problem analysis, problem solving and creative thinking. Also it emphasizes the cultivation of selflearning ability and full exertion of the initiatives and creativity of learner.

\section{CONCEPTS OF TASK-BASED LANGUAGE TEACHING}

The theoretical basis of task-based teaching mode is the constructivism theory. In the task-based teaching, the real situation is simulated through language tasks and the students interact in the situation and play the initiatives to construct the knowledge structure. The basic characteristic of task-based teaching is the teaching activity organized through tasks. The tasks in teaching are not isolated tasks, but a series of tasks designed to achieve the teaching plan. They are the organic parts of the whole teaching activity. The task is in the form of dealing with those simulated or real cases in life. The tasks and their relationship are designed according to the teaching objectives. The students choose the relevant learning strategies purposefully and implement the tasks and participate in activities. This promotes the recombination and construction of knowledge. The students experience the success of knowledge construction. This can accelerate the internalization of knowledge. [1]

In her book of 'task-based learning mode', Willis put forward the concepts of three phases in task-based language teaching.[2] The first phase is the pre-task phase, in which the teacher introduces the main body of the unit and the students are engaged in activities. The goal is to reconstruct the sentences, think and create language as well as reduce the pressure of cognition. The second phase is the main task phase, in which the students are grouped and engaged in activities. They should report to the class how they accomplish the task and what the conclusion is. Finally it is the post-task phase, in which the teacher emphasizes some special forms of language and asks the students to do more practice. The goal is to pay attention to the accuracy of language and encourage the reconstruction of language.

Nunan divides the task-based teaching into six steps.[3] (1) Schema building. In this phase, the students obtain more knowledge of background. The teacher provides the background knowledge related to the topic and the corresponding vocabulary to the students. (2) Controlled practice. The students are asked to engage in the controlled practice, using all the vocabulary, sentence structure taught by the teacher. (3) Authentic listening. The listening material must be related to the topic. The purpose is to make the students contact more authentic materials and expand the language input (4) Focus on linguistic elements. When the students have a preliminary understanding of the relations between the language form, function and meaning, the teacher analyzes the language composition for the students. (5) Provide freer practice. According to previous demonstration, the students are asked to perform more real or simulated communications. To communicate successfully, the students are encouraged to communicate with others using all language knowledge learned. In this phase, the students communicate freely and are less controlled by teacher. (6) Introduce pedagogical task. The teaching content and key should be made clear.

Task-based language teaching is the ideal state of classroom learning, where a large number of language input and output exist. The students can focus their language form and application. At the same time, the motivation of students is fully stimulated. Task-based language teaching can stimulate the learning motivation of students in maximum. Because there are clear and specific courses and mission objectives, learning is no longer passive for students and they begin to use the language to complete certain task actively. Students can choose their own topics of interest, express their ideas, and construct their knowledge structure. To complete the task, students learn to adjust their learning goals and activities. This gradually generates the awareness of autonomous learning. Students will learn to cooperate with others, think independently, and communicate with others.

\section{Discussion ON THE TASK-BASEd TEACHING Mode ON THE BASIS OF CONSTRUCTIVISM}

According to Willis' three-phase theory, the author combines the current situation of college English teaching and proposes some strategies on the task-based teaching as follows.

(i) In the pre-task phase, the teacher provides the students with the language materials related to the tasks. The teacher activate the knowledge background of students, that is, the knowledge stored in the minds of students are inspired and mobilized, concentrated and extracted. The teacher plays the video related to the tasks, provides demonstrations and let the students observe the task. The teacher asks the students to complete the simple activities related to the task, activates the cognitive schema for the students. For instance, in the preparation, the teacher introduces new language material to the students. This makes the students obtain the first perception of new knowledge by presenting new language material to the students. When inputting the language materials to the students, the teacher should activate the experience of students. The teacher provides the students with the environment of language application and thinking related to the topic. [4]

For example, when teaching the topic of 'tourism', the teacher presents the vocabulary and contents as follows. Teacher: Why do lots of people like to travel? Make a list of the reasons. Are there any interesting places in our province or region? What are they? Look at a map of China. Which province are Guilin and Lijiang in? Xinjiang is a region, not a province. Can you name the other regions in China? Which place is farther west, Xinjiang or Yunnan? Please list another region or province in China that has a desert and mountains. Then the teacher can organize the students to perform role play. The situation is presented as follows. Imagine you and your partner want to travel to a place far away from your hometown. You prefer to fly there so that you will be able to stay there longer. Your friend has a different idea. He believes that 
traveling by train or boat is more enjoyable. Please make a dialogue. In the role play, the teacher should present those unfamiliar vocabularies to the students. This can stimulate the motivation of students to communicate with others.

Another example of task-based teaching can be given. For the summary task before class, the teacher asks the students to preview the text content and understand the main idea of the text. Then the teacher asks the students to write the summary of the text. The summary mainly includes the main meaning of text and the comments of students. In each class, the teacher asks the students to make the presentation or dialogue or role play. Then the teacher and other students comment on the performance. After each round, the teacher grades the students and writes the comments. In the oral English training, the abilities of autonomous learning and reading comprehension and writing can be greatly improved. At the same time, the interest of students is also stimulated, as well as the initiatives and enthusiasm. In addition, the consciousness of group collaboration has also been strengthened for the students.

(ii) In the main task phase, the language skills are emphasized. The teacher should focus not only the fluency of language but also the accuracy. At the same time, the teacher encourages the students to reconstruct the language. Teacher should set an appropriate task for students. If the task is more difficult than the cognitive level of students, it does not benefit the learning of students. If the difficulty is less than the cognitive level of students, the students will be weary of learning and lose their interest. In the process of task, the teacher should reduce the pressure of students timely. Teacher can adjust the time and mode of activity and number of participants to erase the learning pressure of students.

There are two kinds of ways to engage in tasks. One is group activity and the other is the personal activity. Group activity includes pair practice, cooperative learning. In the group activities, the language output of students increases substantially. Everyone participates in activities and communicates with others and expresses his own idea. In the group activities, the teacher has the opportunity to focus on the individual student, gives the guidance on language skills to the students timely. Group activities can reduce the anxiety of students. The exchanges between students often lead to less pressure and students usually concentrate on the completion of task and do not have to worry about making mistakes. At the same time, group activities are helpful to stimulate the motivations and interest of students, which promotes the students to help and collaborate with each other. In the group activities, the roles of both teacher and students transform. The students change from the language learners to the users of language. The role of teacher changes from the initiator to the assistant of knowledge construction. The teacher provides the necessary guidance to the students when they need help indeed.[5]

(iii) In the post-task phase, the teacher should provide the opportunity of redoing task to the students and help the students to improve the form of language and achieve the internalization of language. The post-task activities do not be repeated simply by the students, they should be finished by the students independently and completely. The students should improve the accuracy of language as well as the complexity and fluency. By redoing the task again, the students can reflect on their own problems and errors. More accurate relationship between the form and the function of language can be established in the internal language system of students.

When the students redo the task, they actually improve the complexity of language. For instance, they can use the preposition more accurately and speak the language more fluently. When the students are first engaged in group activities, they may pay more attention to the outcome of communication while paying less attention to the form and accuracy of language. When redoing the task, these problems can be solved by the students. For instance, when the students report the results of their group activities to the class, they will pay more attention to the accuracy and complexity of task. They also analyze and reflect on their own problems in task. Possible grammar defects can be found by the students themselves. For example, in the writing training, students should first modify their own compositions by themselves after they finish them. Then they compare their modified compositions with those modified by the teacher, then analyze and summarize the grammar problems. At the same time, the teacher should record the problems that are encountered by the students in doing the tasks. After they finish the tasks, the teacher should solve the problems and provides the opportunity for students to consolidate the language skills.

\section{CONCLUSION}

Traditional English education has its own defects in the aspects of improving students' comprehensive ability and stimulating students' learning initiatives. The task-based teaching on basis of the constructivism theory can well solve these problems. Constructivism theory believes that new language learning must be combined with the existing knowledge of students. At the same time, the knowledge should be acquired in the interaction of social culture. Therefore, the constructivism theory attaches great importance to the role of situation. The purpose of task-based teaching is to design a series of realistic situations where the students learn the language by interacting with the people around.

\section{REFERENCES}

[1] Willis, J. A Framework for Task-Based Learning. London: Longman. 1996.

[2] Ellis, R. Task-based research and language pedagogy. Language Teaching Research 4(3) 193-220, 2000.

[3] Nunan, D. Task-based Language Teaching. Cambridge: Cambridge University Press, 2004.

[4] Ellis, R. Task-based Language Learning and Teaching, Oxford: Oxford University Press, 2003.

[5] Ellis, R. Principles of instructed language learning, System, 33: 209224, 2005. 